Original Contribution

\title{
PRIMARY SCHOOL TEACHERS BEFORE CHOOSING A PERSONAL ORIENTED MODEL FOR TECHNOLOGICAL EDUCATION
}

\author{
G. Ivanov* \\ Faculty of Education, Trakia University, Stara Zagora, Bulgaria
}

\begin{abstract}
The paper considers the problem of selection of primary teachers of person-centered training models, which achieve the objectives of technological training.

These training models based on human interpersonal approach.

The subjects are person-centered training models and object - the choice of an appropriate model to achieve the technological learning in elementary school.

The aim of the study was to substantiate the theoretical and practical reasons for choosing to appropriate person-centered model for technological education in primary school.
\end{abstract}

Key words: technology training, welfare, personal approach and person-centered models choice.

\section{INTRODUCTION}

Characteristic of technological learning in the initial stage of basic education is that it is carried out educational work process. This process is not attractive and desired by younger students if at the work they do - and practical knowledge are brought standard requirements - on the one hand and on the other - if you do not provide enough time for successful completion of the work undertaken. Under "standard conditions" means a requirement to absorb everything all within a regulated time.

In technology education student learns by labor and toil as learn. The result of this is not only practical, but also emotional expression. Participation of the student should not lead to complacency, viewed in physical, emotional and volitional, intellectual and social. As recognition of the efforts made by the student are bigger, easier adaptation to the social nature of work. Recognition of success should not be an end in itself. It has a global orientation - building a training model, which assumes the student the opportunity to study alone. Self is the ultimate goal, because after formal training, each of us going in life, where the new, the challenges, problems and conflicts must be met by prepared for people.

\footnotetext{
*Correspondence to: Georgi Ivanov, Faculty of Education, Trakia University - Stara Zagora
}

This type of training models based on human interpersonal approach, and these models are called person-oriented models. (1)

\section{MATERIALS AND METHODS}

Object of the study are based on humane, personal approach and person-centered training models and object - the choice of an appropriate model to achieve the technological learning in elementary school.

The aim of the study was to substantiate the theoretical and practical reasons for choosing to appropriate person-centered model for technological education in primary school.

Described in the literature personal learning paths to dwell in detail on the model of indirect training (support teaching) developed it $\mathrm{K}$. Rogers (2) of the model for the development of personal consciousness, developed by D. Hunt (3). Training environment that these models suggest features welfare students and respect their individual needs and interests.

\section{RESULTS AND DISCUSSION}

Indirect training is related to the realization of individual approach to specific students and demonstrating welfare. Methodological platform model is the philosophy of humanist educators, advocates of free training.

According to F. Edwards, humanism theory of thought that believes that human beings are 
different from other species, and have abilities that cannot be found in other animals (4). Proponents of humanism focus on the satisfaction of human needs and interests through training. They differ from those who believe that the behavior is the result of controlled conditions, and those who regard the discovery and knowledge are fundamental to human learning. According humanists' man should be seen as an individual, unique human being and to be trained as such.

Typical model no Direct training - supporting teaching - K. Rogers (2) is that they it is focused on the development of high personal self-government and independence, creativity and activity, management of feelings and emotions. Oriented individual, this model gives such a form of education that enables anyone to understand better ourselves, and subsequently take responsibility for their own learning. The focus is on the perspective of the individual and the creation of conditions to promote productive independence which formed people able to draw their own future.

If we assume the system model of human behavior on W. Hewitt (5), which are differentiated four main components cognition, affect system regulatory system behavioral system, the humanistic approach to education focuses on two of them: the regulatory and affective.

Regulatory system acts as a filter to connect the middle and inner thoughts with other thoughts and feelings, as well as to connect the knowledge and feelings in behavior. Affective system transmits a certain character, decorate, reduce or modify the information obtained through the regulatory system, or transmitted by the cognitive system behavior. Information for the 21-st century, which is characterized by uncertainty and constant change, development and the formation of knowledge, skill formation, and education of the emotions, is essential to modern man.

According to N. Gage and D. Berliner (6) the main objectives of the humanistic approach to education can be summarized as follows:

- increasing the self-management of students (development of the regulatory system);

- forming ability in students to take responsibility for their own learning (regulatory and affective systems);

- Development of Creativity (emphasis on divergent aspects of knowledge);

- encourage inquisitiveness and curiosity (exploratory behavior, a function of the and discrepancy in each of the systems);

- stimulate interest in art (development of affective/emotional system. (6)

According to N. Gage, their achievement is possible as a result of training, organizational, functional and technological and subject to the following principles:

First: Students will learn best what they are interested and need to know.

When students have formed the ability to analyze what is important to them and why, when they can manage and organize their behavior to the needs and aspirations, they will learn much more quickly and easily.

Second: Knowing how to learn is more important than the absorption of large amounts of information. (7)

Educators' humanists affirm the statement of J. Gardner that "the main purpose of education is to load individual responsibility for their own learning." (7) They see teaching as an activity through which students will learn how to learn - independent and self- motivated.

The principle is especially relevant in this century in which no amount of information, but its quality and ability to use it are extremely valuable.

Third: Self is the only significant assessment of the work of the student.

Humanistic approach to education does not correspond with the quantitative and qualitative assessments made as a result of standardized tests or other procedures dotsimologichni organized by the teacher. Students' performance should be evaluated not on the basis of comparison with others, but based on their own criteria.

If students will choose what to learn and develop skills in how to learn, they need to exercise and self-esteem. It is an element of self-management behavior and is associated with the ability to set goals, decide on a way to realize and appreciate the level of achievement based on selected criteria.

Fourth: Feelings are as important as facts.

Humanist's teachers do not distinguish between cognitive and affective domain. They embrace the knowledge and feelings as elements of the learning process.

The traditional training is focused on the cognitive domain and ignores the feelings and emotions. From the perspective of humanistic teaching, learning, on the one hand is the acquisition of new information and experience, 
and the other opening of their personal significance.

Fifth: Students learn best in an environment that does not threaten them.

The feeling of fear can be caused by both psychological and physical causes. In the case of essential psychological, created and managed by the teacher - consciously or unconsciously. Very often the feeling of fear, keep learning and changing motivation. (Students are motivated to learn because of fear of failure, not because of the desire for success).

In an educational environment free from threats, students feel safe and this certainly makes them free to learn. They take risks in learning, have a desire to learn and are confident that their self-esteem will not be endangered.

The application of the humanistic approach to training changed the roles of teacher and student. In making educational decisions what, why and how to learn they are equal. Students are those who make their own curriculum and have the right to choose the subject area with which we are dealing. Teachers believe in the need for selfrealization of students and organized learning environment to meet this need. They plan training so as to connect students with meaningful learning activities for them. Under these conditions, students' desire to learn, develop, aspire to discovery, creativity" (S. Roger, op. In N. Gage \& D. Berliner, 1991, p. 479). (2)

Basic form of the humanistic approach to learning is „open learning“. James Rothenberg (8) reveals his character by analyzing the characteristics of the learning environment, the activities of students, evaluation of students, using the time to me, as a teacher.

- Learning comes with integrated materials, combining reading, writing, mathematics, social sciences and natural sciences. It follows the students' interest, stimulated by the teacher and encourages exploration and discovery. Students are given the opportunity to learn at a different pace, to use games to look for information in textbooks or use a range of teaching materials, atmosphere. The classroom is divided into learning places that specialize in areas and topics.

- Activities of students. Students work in small groups, themselves define their tasks and procedures for their application are free to move and to cooperate with other students.

- Assessment of teacher provides feedback to students - the level of his own accomplishments without comparing it to other students.

- School time is used flexibly. Provides the opportunity for continuous and quiet operation, the duration of which is determined by the students.

- The role of the teacher is to be organized, prepare materials to help students in the planning process, working with groups or individual students. (6)

One model of open learning model of supporting the teaching (facilitate teaching), developed by K. Rogers. Its concept is based on his deep belief that people become more sure of themselves when they feel that their subjective experiences and achievements are respected and understood. (9) He differentiates three basic conditions supporting the teaching, namely:

- naturalness and sincerity of the teacher in the learning process. When the teacher facilitator enters into a relationship with the student, not to hide behind a facade, it is much more effective in their work.

- Giving high praise, acceptance and confidence in students. Teacher - facilitator praised the student of his feelings and opinions of his overall personality. $\mathrm{He}$ is concerned about it, without showing possessiveness. The teacher accepts the student as it is, and believe in its potential.

- Demonstrating empathy in education. When the teacher has the ability to understand the reactions of the student, is sensitive to the way he perceives the learning process, creating favorable conditions for learning. (10)

Built on the principles of the approach of K. Rogers (therapy, patient-oriented) model indirectly training - supporting teaching focuses on the partnership between teacher and student in the learning process. The teacher advisor and seeks to help students understand how to become promoters of their own learning - to set goals, paving the way for their achievement, to choose the criteria for assessing performance. The teacher provides information to students about his own progress and helps to solve the problems.

Essential element in the present model of education is backup, the teacher uses in its work with students. It has become a mainstay for students learning, not in the presence $\neg$ to their results. In this sense, communication 
teacher - student is centered around four groups of answers, namely. The teacher advisor and seeks to help students understand how to become promoters of their own learning - to set goals, paving the way for their achievement, to choose the criteria for assessing performance. The teacher provides information of the student for his own progress and helps to solve the problems.

An essential element in the present model of education is enhancement that the teacher uses in its work with students. It has become a mainstay for students learning, not the sentence for their results. In this sense, communication teacher - student is centered on four groups of answers, namely:

The teacher asks questions to students, you want to know the areas of their interest and the way they work: "What evidence do you seek?", "Who is the best source for that?", "Who can best help you?" „Since when are you interested in this problem?" etc.

- Adopting the ideas of students: „That's interesting.", "I understand. "etc.

- Statement of approval: "I think this is a good approach.", "It's obvious.", "I'm impressed by your understanding.", "This is an interesting approach." etc.

- Understanding the feelings and experiences of the students: "I know it's hard.", "I know how much effort you need to get to that information." "I appreciate the long hours you spend on this issue". And so etc. The conduct of the teacher assistant is characterized by:

- Understanding the experiences and feelings of the students;

- Use of student ideas for continuing the teaching interaction;

- Discuss with students;

- Giving a positive assessment of their activities;

- connecting educational content to student's individual needs.

In a large-scale survey of teachers who create an environment of indirectly supporting learning, D. Espy and U. Roebak (11) to reach the conclusion that student behavior is characterized by:

- Increasing the results when measuring selfconcept;

- Achieving better academic results, including math and reading;

- Demonstrate the greater spontaneity and the use of higher levels of thinking;

- No problems with school discipline.

Indirectly supports scientists teaching is a model that individualized training at the center students and creates opportunities for independent and self-directed learning. Aimed at self-realization of each student through its form qualities and skills, that meets the continuous learning.

Without denying the basic knowledge, the model focuses on the more complex levels of behavioral expression of students related to skills used no information, its analysis, synthesis and evaluation. Change in the traditional roles of the two bodies, teacher and student, leads to a qualitatively new learning environment that is characterized by an atmosphere of learning, stimulating creativity, curiosity, risk-taking satisfaction from the results, etc.

\section{CONCLUSIONS}

To the presented models can also make critical comments and admiration. Each of them differently attacks the main objective of training and education - developing skills the student to learn alone, but in a more global aspect - lifelong learning. Achieving this goal cannot be achieved if the teacher does not have the educational resources - textbooks that provide substantive requirements the student to move with its growth in the utilization of educational content - on the one hand and on the other - to build significant personality. Unfortunately, in the existing textbooks, educational content is oriented so that all calls to it. There are no opportunities for individualized and differentiated learning.

Who and or what person-centered models of teaching and teacher will choose what textbooks will it happen is a matter of informed choice.

\section{REFERENCES}

1. Marinella, M. Teaching and learning. Astarte, Veliko Tarnovo, 2002., P.182 Rogers, C.R. \& Freiberg, H.J. (1994). Freedom to Learn (3rd Ed). Columbus, OH: Merrill/Macmillan.

2. Rogers, C.R. \& Freiberg, H.J. (1994). Freedom to Learn (3rd Ed). Columbus, $\mathrm{OH}$ : Merrill/Macmillan.

3. Hunt, E.B. (1962). Concept Learning. New York: Wiley.

4. Edwords, F. (1989). What is Humanism ${ }^{\circledR}$ Amherest, NY\& American Humanist As $\neg$ sociation. http://www.jcn.com/humanism.html

5. Huitt, W. (1995). A systems model of the teaching/learning process. Valdosta, GA:College of Education, Valdosta State University. 
6. Gage, N.\&Berliner, D. (1991). Educational Psychology (5-th ed.). Boston: Houghton. Mifflin

7. Gardner, H. (1999). Intelligence Reframed: Multiple Intelligence for the 21-st century, New York.

8. Rothenberg, J. (1989) The open classroom considered. Elementary School Journal, 90, 69-86.
9. Thome, B. (1992) Carl Rogers, London: Sage.

10.Kirschenbaum, H. and V. L Henderson (eds.) (1990) The Carl Rogers Reader, London: Constable, pages 304-311

11.Aspy, D. \& Roebuck, F. (1977). Kids don.ro learn from people they don.ro like. Amherst, MA: Human Resources Development Press. 